\title{
The integral membrane FtsW protein and peptidoglycan synthase PBP3 form a subcomplex in Escherichia coli
}

Correspondence Martine Nguyen-Distèche mng.disteche@ulg.ac.be Tanneke den Blaauwen t.denblaauwen@uva.nl

Received 2 April 2010 Revised 9 September 2010 Accepted 9 September 2010

\author{
Claudine Fraipont, ${ }^{1} \dagger$ Svetlana Alexeeva, ${ }^{2} \dagger$ Benoît Wolf, ${ }^{1} \ddagger$ \\ René van der Ploeg, ${ }^{2}$ Marie Schloesser, ${ }^{1}$ Tanneke den Blaauwen ${ }^{2}$ \\ and Martine Nguyen-Distèche ${ }^{1}$
${ }^{1}$ Centre d'Ingénierie des Protéines, Université de Liège, Institut de Chimie, B6a, B-4000 Sart-Tilman, Belgium \\ ${ }^{2}$ Molecular Cytology, Swammerdam Institute for Life Sciences, University of Amsterdam, Science \\ Park 1098 XH Amsterdam, The Netherlands
}

During the cell cycle of rod-shaped bacteria, two morphogenetic processes can be discriminated: length growth of the cylindrical part of the cell and cell division by formation of two new cell poles. The morphogenetic protein complex responsible for the septation during cell division (the divisome) includes class A and class B penicillin-binding proteins (PBPs). In Escherichia coli, the class B PBP3 is specific for septal peptidoglycan synthesis. It requires the putative lipid II flippase FtsW for its localization at the division site and is necessary for the midcell localization of the class A PBP1B. In this work we show direct interactions between FtsW and PBP3 in vivo and in vitro by FRET (Förster resonance energy transfer) and co-immunoprecipitation experiments. These proteins are able to form a discrete complex independently of the other cell-division proteins. The K2-V42 peptide of PBP3 containing the membrane-spanning sequence is a structural determinant sufficient for interaction with FtsW and for PBP3 dimerization. By using a two-hybrid assay, the class A PBP1B was shown to interact with FtsW. However, it could not be detected in the immunoprecipitated FtsW-PBP3 complex. The periplasmic loop 9/10 of FtsW appeared to be involved in the interaction with both PBP1B and PBP3. It might play an important role in the positioning of these proteins within the divisome.

\section{INTRODUCTION}

In every generation, bacteria require morphogenetic protein machineries to produce two identical sacculi by the enlargement and division of one sacculus (Begg et al., 1990; Nanninga, 1998; Errington, 2003). The wall peptidoglycan is a key element in preserving the cell integrity and is related to the bacterial morphogenesis. Peptidoglycan synthesis is catalysed by penicillin-binding protein (PBP) classes A and B (the targets of $\beta$-lactams) (Goffin \& Ghuysen, 1998). Escherichia coli contains three transglycosylase/transpeptidase class A PBPs, PBP1A, PBP1B and PBP1C, which catalyse the formation of polymeric peptidoglycan, and two class B PBPs, the monofunctional

†These authors contributed equally to this work.

$\ddagger$ Present address: Eurogentec SA, Liège Science Park, Rue du Bois Saint Jean 5, B-4102 Seraing, Belgium.

Abbreviations: FRET, Förster resonance energy transfer; PBP, penicillinbinding protein; TMS, transmembrane segment.

Two supplementary figures are available with the online version of this paper. transpeptidases PBP2 and PBP3 (also called FtsI), which catalyse peptide cross-linking (Höltje, 1998; Sauvage et al., 2008). These peptidoglycan synthases work in coordination with a number of other proteins in two morphogenetic networks, the elongasome during elongation and the divisome during division (den Blaauwen et al., 2008).

The components of the divisome include at least 12 essential cell-division proteins, FtsZ, FtsA, ZipA, FtsE, FtsX, FtsK, FtsQ, FtsL, FtsB, FtsW, PBP3, FtsN, and a number of other proteins including the main peptidoglycan polymerase $\mathrm{PBP} 1 \mathrm{~B}$, and the AmiC and EnvC hydrolases (den Blaauwen et al., 2008). To initiate cell division, the GTP-binding tubulin-like FtsZ protein forms an intracellular ring at the division site (Addinall \& Lutkenhaus, 1996; Löwe \& Amos, 1998). It is stabilized by FtsA, ZapA and ZipA, and this Z-ring serves as a cytoskeletal scaffold for the assembly of the other proteins of the cell-division machinery (den Blaauwen et al., 2008), which assembles in two steps (Aarsman et al., 2005). Some proteins can form a subcomplex, such as FtsQ, FtsL and FtsB (Buddelmeijer \& Beckwith, 2004). 
The cytoplasmic transmembrane protein $\mathrm{FtsW}$ includes 10 transmembrane segments (TMSs) (Lara \& Ayala, 2002) and belongs to the SEDS family (for shape, elongation, division and sporulation) (Henriques et al., 1998) (Fig. 1). It interacts with PBP3, FtsQ, FtsL and FtsN in a bacterial twohybrid assay (Di Lallo et al., 2003; Karimova et al., 2005) and is required to recruit PBP3 to the division site (Mercer \& Weiss, 2002). It has been proposed to integrate signals between the cytoplasmic (FtsZ, FtsA, ZipA and FtsK) and the periplasmic (FtsK, FtsQ, FtsL, FtsB, PBP3 and FtsN) components of the divisome (Margolin, 2000), but also to function as a flippase to translocate the lipid II from the cytoplasm to the periplasmic machinery of peptidoglycan assembly (Matsuhashi, 1994). The observation that a ZapA-FtsW fusion and a ZapA-PBP3 fusion can recruit PBP3 and FtsW, respectively, in cells depleted of FtsA or FtsQ to the divisome in cells without a visible constriction suggests the formation of a pre-formed complex between these proteins (Goehring et al., 2006). The interaction could take place through one of the TMSs of FtsW, as the first 56 residues of PBP3 (containing the TMS) are sufficient to localize it to the division site (Piette et al., 2004). The $9 / 10$ loop of FtsW (between TMSs 9 and 10) could also be involved, since the double FtsW(P368A;P375A) mutant (Fig. 1), while localizing itself at midcell, prevents the localization of PBP3 at the division site (Pastoret et al., 2004).

PBP3 interacts directly with PBP1B (Bertsche et al., 2006), which is essential in the absence of its paralogue PBP1A (Suzuki et al., 1978). PBP1B localizes at the lateral wall during elongation and at the division site during septation, and its localization at the division site depends on the presence of PBP3 but not on its activity (Bertsche et al., 2006). These proteins might thus act together to form the peptidoglycan of the two new cell poles. PBP3 also interacts

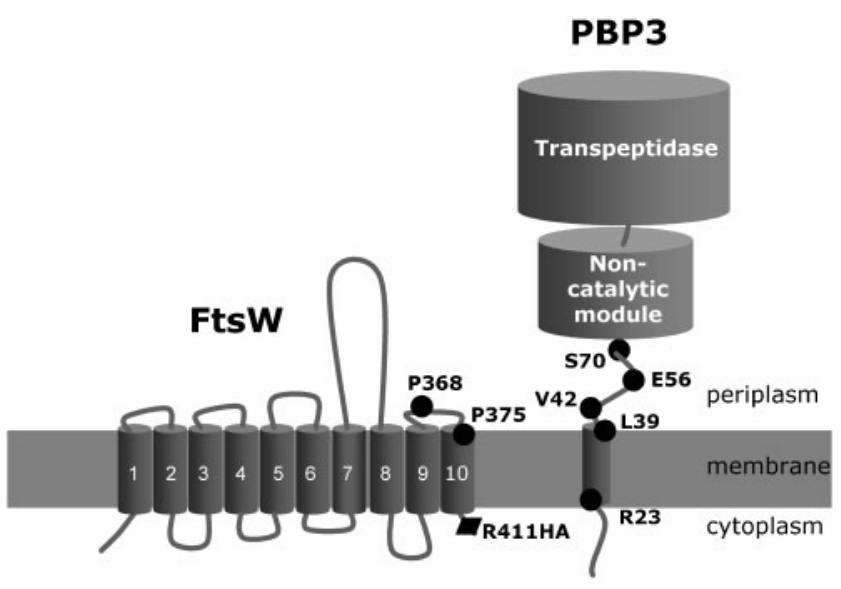

Fig. 1. Topology of the transmembrane protein FtsW and the transpeptidase PBP3. The positions of the modified amino acids discussed are shown. The HA tag is inserted between R411 and G412. with FtsN, which interacts with PBP1B. FtsN stimulates PBP1B activity (Müller et al., 2007). Thus FtsN might coordinate or modulate the activities of a PBP1B-PBP3 complex in the cell.

In this work, we report a direct interaction between FtsW and PBP3 by in vivo FRET (Förster resonance energy transfer) experiments and in vitro isolation of the FtsWPBP3 complex by co-immunoprecipitation. FtsW was also shown to interact with PBP1B using a two-hybrid assay, and the periplasmic loop 9/10 of FtsW seemed to be involved in this interaction. A three-protein complex FtsW-PBP3-PBP1B could not be isolated.

\section{METHODS}

Bacterial strains, oligonucleotides and media. Bacterial strains are described in Table 1. Oligonucleotides were from Eurogentec. The rich medium used was Luria-Bertani (LB) medium supplemented with ampicillin (50 or $100 \mu \mathrm{g} \mathrm{ml}^{-1}$ ), chloramphenicol $(20$ or $30 \mu \mathrm{g}$ $\left.\mathrm{ml}^{-1}\right)$, tetracycline $\left(12.5 \mu \mathrm{g} \mathrm{ml}^{-1}\right)$ and/or IPTG $(0.01,0.1$ or $1 \mathrm{mM})$ when appropriate. For the FRET experiment, the minimal medium GB1 was used (Bertsche et al., 2006).

\section{Plasmid construction}

pDML2454, pDML2455 and pDML2456. Plasmid pDML2487 carrying the fragment encoding GFP-PBP3(K2-V42) (Piette et al., 2004) was digested by $M l u \mathrm{I}$ and ScaI and cloned into the MluI and SmaI sites of pBT/ftsI-linker (Bertsche et al., 2006). The NotI-HindIII DNA fragment encoding PBP3(M1-V42) was excised from the resulting plasmid and inserted into the corresponding sites of pDML2453 to create pDML2454, which allows the production of $\mathrm{T} 18-\left(\mathrm{G}_{4} \mathrm{~S}\right)_{3}-\mathrm{PBP} 3(\mathrm{M} 1-\mathrm{V} 42)$.

The modified ftsI gene encoding PBP3(R23C) or PBP3(L39P) was amplified by PCR using plasmids pDSW562 or pDSW566 (gift of D. Weiss) as template and oligonucleotides $5^{\prime}$-TAGGCGGCCGCACTTAAGGAGCTCATGAAAGCAGCGGCGAAAACGCAG-3' and $5^{\prime}$ GTTCAGTTCGCGATAAACC-3' as primers (NotI, SacI and NruI sites are underlined). The PCR fragment was cloned into pGEM-T Easy (Promega), sequenced, digested with $M l u \mathrm{I}$ and $\mathrm{SacI}$ and inserted into the same sites of pDML2451a (Bertsche et al., 2006). The resulting plasmids pDML2455 and pDML2456 code for T18- $\left(\mathrm{G}_{4} \mathrm{~S}\right)_{3}-$ PBP3(R23C) and T18- $\left(\mathrm{G}_{4} \mathrm{~S}\right)_{3}-\mathrm{PBP} 3(\mathrm{~L} 39 \mathrm{P})$, respectively.

pDML2445. The fragment resulting from the NdeI and MluI digestion of plasmid pDML2413 encoding FtsW(P368A;P375A) (Pastoret et al., 2004) was inserted into the same sites of pDML2424 encoding HA tag-FtsW (Pastoret et al., 2004). The SnaBI-HindIII fragment encoding the HA tag-FtsW mutant was exchanged with the corresponding fragment of pDML2443a encoding T25- $\left(\mathrm{G}_{4} \mathrm{~S}\right)_{3}-\mathrm{FtsW}$ (Derouaux et al., 2008). The resulting plasmid pDML2445 allows the production of $\mathrm{T} 25-\left(\mathrm{G}_{4} \mathrm{~S}\right)_{3}-\mathrm{FtsW}(\mathrm{P} 368 \mathrm{~A} ; \mathrm{P} 375 \mathrm{~A})-\mathrm{HA}$ tag.

pSA060, pSA062, pSA063, pSA066, pSA068 and pSA069. Fragments resulting from the EcoRI and HindIII digestion of the pDSW234 (Weiss et al., 1999) and pDML2414 (Pastoret et al., 2004) plasmids, carrying the coding sequences for PBP3 and FtsW respectively, were inserted between the same sites of pSAV047 (mCherry) and pSAV058 (mKO) to give pSA060, pSA063, pSA066 and pSA069, coding for the fusion proteins $\mathrm{mCh}-\mathrm{PBP} 3, \mathrm{mCh}-\mathrm{FtsW}$, $\mathrm{mKO}-\mathrm{PBP} 3$ and $\mathrm{mKO}-\mathrm{FtsW}$, respectively. The fusion GFPPBP3(K2-V42) (Piette et al., 2004) was digested by EcoRI and HindIII and the fragment cloned into the corresponding sites of 
Table 1. Bacterial strains with relevant properties and references

\begin{tabular}{|c|c|c|}
\hline Strain & Relevant genetic marker(s) or features & Source \\
\hline LMC510 & LMC500 ftsI2158(ts) & Taschner et al. (1988) \\
\hline Top10F' & 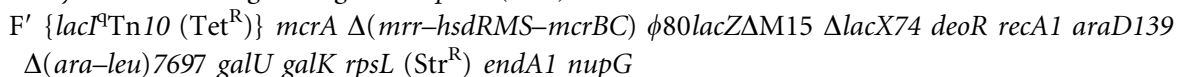 & Invitrogen \\
\hline
\end{tabular}

pSAV047 (mCherry) and pSAV058 (mKO), yielding pSA062 and pSA068, coding for mCherry-PBP3(K2-V42) and mKO-PBP3(K2$\mathrm{V} 42)$, respectively. The mKO sequence was obtained from pmKO1-S1 (MBL, Nagoya, Japan). Tandem (mCherry-mKO, pSAV050), mCherry (pSAV047), mKO (pSAV058), and 'empty' plasmids pTHV037 (Amp) and pSAV057 (Cam) were used as controls (Alexeeva et al., 2010). The correctness of all constructs was confirmed by sequencing.

Measurement of $\beta$-galactosidase activity in liquid cultures. $\beta$ Galactosidase activity was measured in cell extracts from liquid cultures as described by Karimova et al. (2005). A level of $\beta$ galactosidase activity at least fourfold higher than that measured for E. coli BTH101 cells producing T18/T25 (16 or $72 \mathrm{U}$ per mg dry weight of bacteria without or with IPTG respectively) was considered to indicate an interaction.

FRET experiment. For the FRET experiment we use a red-shifted fluorescent protein pair with $\mathrm{mKO}$ (Karasawa et al., 2004) as a donor and mCherry (Shaner et al., 2004) as an acceptor. E. coli LMC500 was co-transformed with two appropriate vectors. When a single protein was to be expressed, a non-coding second plasmid was cotransformed. Each experiment included the mKO-mCherry tandem fusion as a positive control, $\mathrm{mKO}$ and mCherry expressed as two separate proteins in the cell, mCherry-(fusion to protein of interest) expressed with unfused $\mathrm{mKO}$, and $\mathrm{mKO}-$ (fusion to protein of interest) expressed with unfused mCherry as negative controls. Transformants were grown in TY, $0.4 \%$ glucose $(\mathrm{w} / \mathrm{v})$ supplemented with $100 \mu \mathrm{g}$ ampicillin $\mathrm{ml}^{-1}$ and $25 \mu \mathrm{g}$ chloramphenicol $\mathrm{ml}^{-1}$. After $8 \mathrm{~h}$ growth, the cultures were diluted $1: 12500$ in $25 \mathrm{ml}$ minimal medium GB1 and grown overnight at $28{ }^{\circ} \mathrm{C}$. Subsequently, the cultures were diluted and cells were grown in minimal medium at $28{ }^{\circ} \mathrm{C}$ for $\sim 40 \mathrm{~h}$, keeping the $\mathrm{OD}_{450}$ below 0.2 by regular dilution of the cultures in pre-warmed medium. Fusion protein expression was initiated by addition of $10 \mu \mathrm{M}$ IPTG to $40 \mathrm{ml}$ cultures. Based on the determined growth rates, the cultures were diluted appropriately and cell growth in the presence of IPTG inducer was allowed for the next $6 \mathrm{~h}$ until the cultures reached an $\mathrm{OD}_{450}$ of 0.2 . In the case of LMC510 [PBP3(ts)], after growth at $28{ }^{\circ} \mathrm{C}$ as described above, the cultures were split in two and one part was grown at $28{ }^{\circ} \mathrm{C}$, whereas the other part was grown at $42{ }^{\circ} \mathrm{C}$ for two mass doublings. The cultures were fixed by addition of $2.8 \%(\mathrm{v} / \mathrm{v})$ formaldehyde and $0.04 \% \quad(\mathrm{v} / \mathrm{v})$ glutaraldehyde while shaking in a water bath. After $15 \mathrm{~min}$ incubation, cells were collected by centrifugation $\left(4{ }^{\circ} \mathrm{C}, 10 \mathrm{~min}\right.$, $8000 \mathrm{~g}$ ), washed once with PBS $(140 \mathrm{mM} \mathrm{NaCl}, 27 \mathrm{mM} \mathrm{KCl}$, $10 \mathrm{mM} \mathrm{Na} \mathrm{HPO}_{4}, 2 \mathrm{mM} \mathrm{KH} \mathrm{PO}_{4}, \mathrm{pH} \mathrm{7.2)}$ and resuspended in PBS. The samples were incubated overnight at $37^{\circ} \mathrm{C}$ to allow maturation of $\mathrm{mKO}$. After adjustment of the $\mathrm{OD}_{450}$ of the cell suspension to exactly 1.00 , spectra were recorded with a fluorescence spectrophotometer (QuantaMaster 2000-4, PTI) with a red-optimized setup: R928 PMT tube $(185-900 \mathrm{~nm}), 500 \mathrm{~nm}$ blaze (1200 lines $\left.\mathrm{mm}^{-1}\right)$ in both excitation and emission gratings. The spectra at donor $\left(\mathrm{mKO}, \lambda_{\mathrm{D}} 538 / 6 \mathrm{~nm}\right)$ and acceptor (mCherry, $\lambda_{\mathrm{A}} 590 / 6 \mathrm{~nm}$ ) excitation wavelengths were recorded for each sample. For each experiment, reference spectra were recorded from cells expressing only mKO or only mCherry proteins, and reference background spectra were recorded from cells bearing two non-coding plasmids. The reference spectra were used to calculate contributions of donor, acceptor and background to the total spectrum of the experimental samples measured at $\lambda_{\mathrm{D}}$ using least-square fitting. Sensitized emission and apparent efficiency of energy transfer $E f_{\mathrm{A}}$ were derived essentially as described previously (Clegg, 1992; Clegg et al., 1992; Gadella, 2009; Alexeeva et al., 2010).

Preparation of fusion proteins and affinity chromatography. $E$. coli LMC500 cells harbouring pDML2424 (Pastoret et al., 2004), encoding the HA tag-FtsW(R411HA), or pDSW234 (Weiss et al., 1999), encoding GFP-PBP3, were grown at $37^{\circ} \mathrm{C}$ in Luria-Bertani (LB) medium supplemented with appropriate antibiotics to an $\mathrm{OD}_{600}$ of 0.4. Then protein expression was induced for $4 \mathrm{~h}$ by addition of $1 \mathrm{mM}$ IPTG. Cells were suspended in $8 \mathrm{ml} 30 \mathrm{mM}$ Tris/ $\mathrm{HCl} \mathrm{pH} 8$, $5 \mathrm{mM}$ EDTA, $100 \mu \mathrm{g}$ lysozyme $\mathrm{ml}^{-1}, 5 \mathrm{mM} \mathrm{MgCl}_{2}, 0.01 \mathrm{U}$ benzonase, $100 \mu \mathrm{M}$ PMSF. After $20 \mathrm{~min}$ incubation at $4{ }^{\circ} \mathrm{C}, 32 \mathrm{ml}$ cold water was added and the mixture was centrifuged for $1 \mathrm{~h}$ at 18000 r.p.m. $(38830 \mathrm{~g})$. The membrane fraction was then resuspended in $600 \mu \mathrm{l} 10 \mathrm{mM}$ Tris $\mathrm{pH}$ 8.0, $10 \%(\mathrm{w} / \mathrm{v})$ glycerol, $10 \%(\mathrm{v} / \mathrm{v})$ ethylene glycol, $0.5 \mathrm{M} \mathrm{NaCl}$ (TGE buffer) and centrifuged for $15 \mathrm{~min}$ at 13200 r.p.m. $(13600 \mathrm{~g})$. The membrane proteins were solubilized in $300 \mu \mathrm{l} 50 \mathrm{mM}$ Tris/HCl pH 7.9, $150 \mathrm{mM} \mathrm{NaCl}, 35 \%$ (v/v) glycerol, $1.25 \%(\mathrm{w} / \mathrm{v})$ octyl glucoside (solubilization buffer). After 15 min incubation on ice, samples were centrifuged for $15 \mathrm{~min}$ at 13200 r.p.m. $(13600 \mathrm{~g})$. The supernatant contained solubilized membrane proteins.

Mouse antibodies (IgG1) directed against GFP $(20 \mu \mathrm{l})$ were incubated at room temperature for $60 \mathrm{~min}$ in the presence of $200 \mu \mathrm{l}$ magnetic matrix Dynabeads Protein G (Dynal Biotech) in $25 \mathrm{mM}$ HEPES buffer $\mathrm{pH} 7.5,150 \mathrm{mM} \mathrm{NaCl}, 0.1 \%$ (w/v) Triton X-100, $10 \%(\mathrm{v} / \mathrm{v})$ glycerol. The matrix/antibodies mixture was washed twice with the same buffer to remove excess antibodies.

Co-immunoprecipitation. This was carried out as follows. A $125 \mu \mathrm{l}$ sample of each solubilized protein was incubated under agitation at $4{ }^{\circ} \mathrm{C}$ with $50 \mu$ matrix (Dynabeads Protein G coupled to GFP antibodies) for $90 \mathrm{~min}$; the matrix was then washed five times with solubilization buffer. Elution was carried out by incubation for $30 \mathrm{~min}$ at room temperature with $7.5 \mu \mathrm{l} 66.6 \mathrm{mM}$ Tris/ $\mathrm{HCl} \mathrm{pH} 6.8$, $11 \%(\mathrm{v} / \mathrm{v})$ glycerol, $0.001 \%$ bromophenol blue, $1 \%(\mathrm{w} / \mathrm{v})$ SDS and $3.3 \%(\mathrm{v} / \mathrm{v}) \beta$-mercaptoethanol. The eluted proteins were analysed by $10 \%$ SDS-PAGE, followed by Western blotting using antibodies directed against the HA tag.

Fluorescence detection and Western blotting. After SDS-PAGE, the fluorescence of the GFP-protein fusions was detected directly on the gel using an FX Molecular Imager (Bio-Rad) with the same parameter set as designed for fluorescein isothiocyanate detection (excitation by $488 \mathrm{~nm}$ wavelength Ar ion laser with a 515-545 nm band emission filter). Western blotting was then carried out as follows: the separated proteins were electro-transferred to a PVDF membrane, blocked with ECL blocking agent washed and probed by 
incubation for $1 \mathrm{~h}$ with monoclonal anti-HA-peroxidase [HighAffinity (3F10) Roche]. The proteins were visualized by enhanced chemiluminescence (ECL kit, GE Healthcare).

\section{RESULTS}

\section{In vivo FtsW-PBP3 interaction revealed by FRET}

To study the interaction between FtsW and PBP3, we used the Förster resonance energy transfer (FRET) technique. FRET occurs between two appropriately chosen fluorophores only when the distance separating them is less than $10 \mathrm{~nm}$ (Förster, 1948). FtsW and PBP3 were fused to the C-terminal end of mKusabira Orange (mKO) fluorescent protein (Karasawa et al., 2004), the donor, and mCherry red fluorescent protein (Shaner et al., 2004), the acceptor. Previously it was shown that GFP fusions of PBP3 and FtsW are functional (Piette et al., 2004; Pastoret et al., 2004) using the same linker between the fluorescent protein and the cell division proteins as in the mCherry and mKO fusions. E. coli LMC500 was co-transformed with appropriate vectors. Transformants were grown to steady state as described in Methods. Fusion protein expression was initiated by addition of $10 \mu \mathrm{M}$ IPTG to $40 \mathrm{ml}$ cultures for the next $6 \mathrm{~h}$ until the cultures reached an $\mathrm{OD}_{450}$ of 0.2 . The spectra were recorded with a fluorescence spectrophotometer. Sensitized emission and apparent efficiency of energy transfer $E f_{\mathrm{A}}$ were derived essentially as described previously (Alexeeva et al., 2010).

The results showed a positive FRET signal between FPFtsW and FP-PBP3 (FP, fluorescent protein) that was two to three times higher than that of the negative controls (Fig. 2). Significance of the data was assessed using the unpaired double-sided $t$-test versus the negative control. All samples returning a $P$-value of the $t$-test below 0.05 were considered statistically significant for the particular sample. For the mKO-PBP3 and mCherry-FtsW sample a $P$ value of 0.006 ( $99.4 \%$ confidence interval) versus the negative control $\mathrm{mKO}$ and mCherry-FtsW was found. In general we found that an average $E f_{\mathrm{A}}$ of $1.2 \%$ represents the percentage of bystander FRET in the membrane in our expression system (Alexeeva et al., 2010). A FRET signal between two FP-PBP3 molecules was also detected (Fig. 2, sample O3 + Ch3) but no significant FRET signal between two FtsW molecules could be detected (Fig. 2, sample $\mathrm{OW}+\mathrm{ChW}$ ). These results indicate that FtsW directly interacts with PBP3 and that PBP3 forms dimers.

\section{In vitro FtsW-PBP3 interaction by co- immunoprecipitation}

In order to show that FtsW and PBP3 form a complex, coimmunoprecipitation experiments were carried out. Proteins of membrane fractions isolated from E. coli LMC500 expressing GFP-PBP3 (Piette et al., 2004) or HA tag-FtsW (containing an antigenic YPYDVPDYA peptide epitope inserted between R411 and G412) (Pastoret et al., 2004) were solubilized in the presence of $1.25 \%(\mathrm{w} / \mathrm{v})$ octyl glucoside as described in Methods. The protein extracts were mixed and incubated with Dynabeads Protein G coupled to GFP antibodies. After washing, the retained proteins were eluted and analysed by SDS-PAGE followed by fluorescence detection and Western blotting (see Methods). Fig. 3 shows that the GFP-PBP3 and HA tagFtsW were co-eluted from Dynabeads Protein G coupled to GFP antibodies (lanes 9 in Fig. $3 \mathrm{a}$ and b). The HA tagFtsW specifically bound to the GFP-PBP3 since it was not

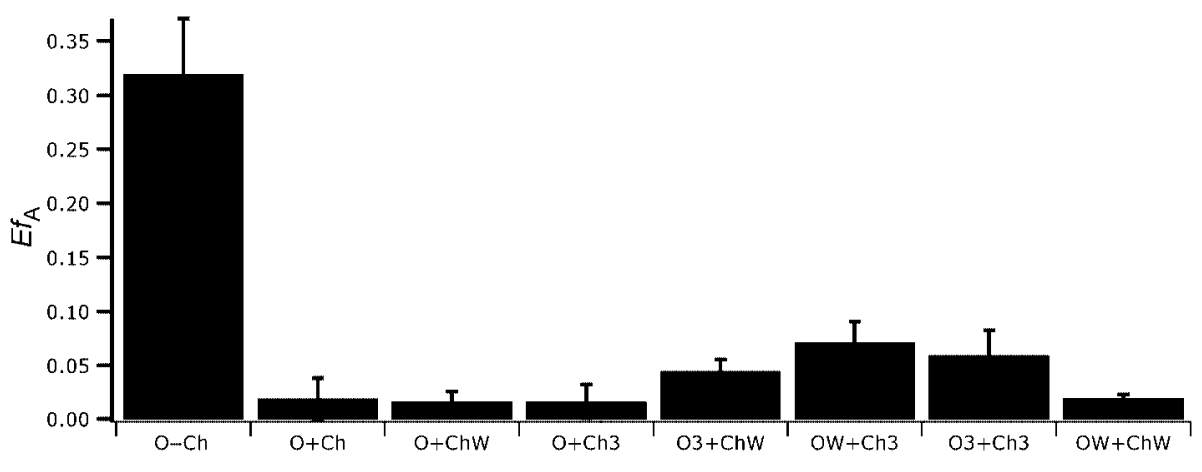

Fig. 2. FRET efficiency $\left(E f_{\mathrm{A}}\right)$ for various combinations of $m K O$ and $m$ Cherry fusions. For each experiment reference spectra were recorded from cells expressing only $\mathrm{mKO}$ or only $\mathrm{mCherry}$ proteins, and reference background spectra were recorded from cells bearing two non-coding plasmids. The reference spectra were used to calculate the contributions of donor, acceptor and background to the total spectrum of the experimental samples measured at $\lambda_{\mathrm{D}}$ using least-square fitting (Alexeeva et al., 2010). O-Ch, tandem expression of $\mathrm{mKO}$ and $\mathrm{mCh}$ (as positive control, $n=24) ; \mathrm{O}+\mathrm{Ch}$, separately expressed $\mathrm{mKO}$ and $\mathrm{mCh}$ (as negative control, $n=24) ; \mathrm{O}+\mathrm{ChW}$, expression of $\mathrm{mKO}$ and $\mathrm{mCh}-\mathrm{FtsW}$ (as negative control, $n=4$ ); $\mathrm{O}+\mathrm{Ch} 3$, expression of $\mathrm{mKO}$ and mCh-PBP3 (as negative control, $n=4) ; \mathrm{O} 3+\mathrm{ChW}$, expression of mKO-PBP3 and mCh-FtsW $(n=4) ; \mathrm{OW}+\mathrm{Ch} 3$, expression of mKO-FtsW and mCh-PBP3 $(n=5)$; O3 + Ch3, expression of mKO-PBP3 and $\mathrm{mCh}-\mathrm{PBP} 3(n=4) ; \mathrm{OW}+\mathrm{ChW}$, expression of $\mathrm{mKO}-\mathrm{FtsW}$ and $\mathrm{mCh}-\mathrm{FtsW}(n=2)$. 


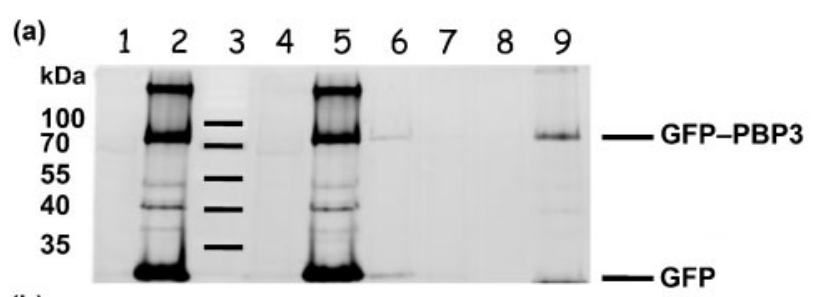

(b)

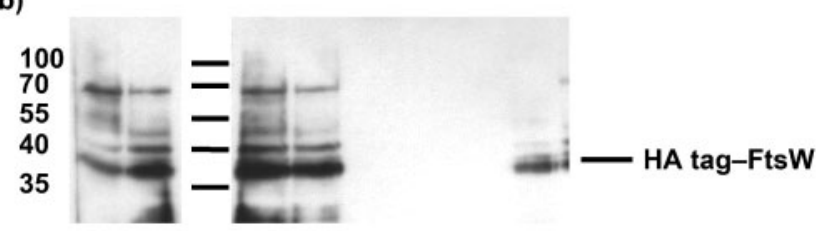

(c)

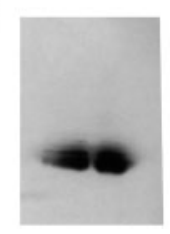

Fig. 3. Interaction between FtsW and PBP3. (a) Fluorescent detection of GFP-PBP3 and (b) immunodetection of HA tagFtsW after $10 \%$ SDS-PAGE. Lanes: 1, solubilized proteins from E. coli strain overexpressing $\mathrm{HA}$ tag-FtsW alone (negative control); 2, mixture of solubilized proteins from $E$. coli strains overexpressing HA tag-FtsW or GFP-PBP3; 3, molecular mass markers; 4, negative control: flowthrough; 5, HA tag-FtsW and GFP-PBP3: flowthrough; 6, negative control: wash; 7, HA tagFtsW and PBP3: wash; 8, negative control: eluate ; 9, HA tagFtsW and GFP-PBP3: eluate. (c) Left, HA tag-FtsW and GFPPBP3 eluate; right, HA tag-FtsW(P368A;P375A) and PBP3 eluate (immunodetection of $\mathrm{HA}$ tag-FtsW).

retained and eluted from the Dynabeads Protein G coupled to GFP antibodies in the absence of GFP-PBP3 (Fig. 3a, b, lane 8). This experiment was repeated more than three times with the same results. These results indicate that FtsW and PBP3 are able to form a discrete complex. PBP1B could not be detected reproducibly within the subcomplex when the GFP-PBP3, HA tag-FtsW and His tag-PBP1B proteins expressed from E. coli LMC500 were solubilized with detergent, mixed and incubated with the Dynabeads Protein G coupled to GFP antibodies as described above. Interestingly, the HA tag-FtsW(P368A;P375A) mutant, which reduces the localization of $\mathrm{PBP} 3$ at the division site (Pastoret et al., 2004), still bound to GFP-PBP3 (Fig. 3c).

\section{The PBP3 transmembrane segment (TMS) is involved in the interaction with FtsW}

It was shown previously that the periplasmic loop 9/10 of FtsW (Fig. 1) was involved in PBP3 recruitment at the division site (Pastoret et al., 2004). It was also shown that the structural determinants required to target PBP3 to the division site are present in the first 56 residues of PBP3 and that $\mathrm{PBP} 3(\mathrm{~K} 2-\mathrm{V} 42)$ is weakly recruited to the division site
(Piette et al., 2004). Lpp-PBP3, which is obtained by replacement of the first 41 residues of $\mathrm{PBP} 3$ by the Lpp signal peptide, does not interact with FtsW (Derouaux et al., 2008). Changing R23 to $\mathrm{C}$ or $\mathrm{L} 39$ to $\mathrm{P}$, located at both ends of the TMS of PBP3, severely impairs the localization of the protein at the division site but not its membrane insertion (see Supplementary Fig. S1, available with the online version of this paper) or its ability to bind penicillin (Wissel \& Weiss, 2004), suggesting that the TMS of the protein is involved in the recruitment of the protein to the division site. In order to define which portions of the proteins were involved in the interactions, we analysed the ability of FtsW mutants to interact with $\mathrm{PBP} 3$ and the effect of PBP3 mutants on the interaction with FtsW by using the Cya two-hybrid assay (Karimova et al., 2005; Bertsche et al., 2006). The Cya T18 and Cya T25 fragments of the adenylate cyclase (Cya) were fused to the $\mathrm{N}$-terminus of FtsW mutant and PBP3 mutants, respectively, through a $\left(\mathrm{G}_{4} \mathrm{~S}\right)_{3}$ linker to test their interaction with the respective T25- $\left(\mathrm{G}_{4} \mathrm{~S}\right)_{3}-\mathrm{FtsW}$ and T18- $\left(\mathrm{G}_{4} \mathrm{~S}\right)_{3}-\mathrm{PBP}$. These two wildtype fusion proteins were functional in vivo as described previously (Derouaux et al., 2008; Bertsche et al., 2006). The production of $\beta$-galactosidase was quantitatively measured in cell extracts from cultures grown in LB medium in the absence of IPTG. As shown in Fig. 4 , the $\beta$-galactosidase activity of the cya-deficient $E$. coli BTH101 co-producing T18- $\left(\mathrm{G}_{4} \mathrm{~S}\right)_{3}-\mathrm{PBP} 3$ and $\mathrm{T} 25-\left(\mathrm{G}_{4} \mathrm{~S}\right)_{3}-\mathrm{FtsW}(\mathrm{P} 368 \mathrm{~A} ; \mathrm{P} 375 \mathrm{~A})$ under non-induced conditions was $64 \pm 18 \%$ of that of the wild-type fusion pairs. This result indicates that the interaction was slightly affected by the mutations and is in

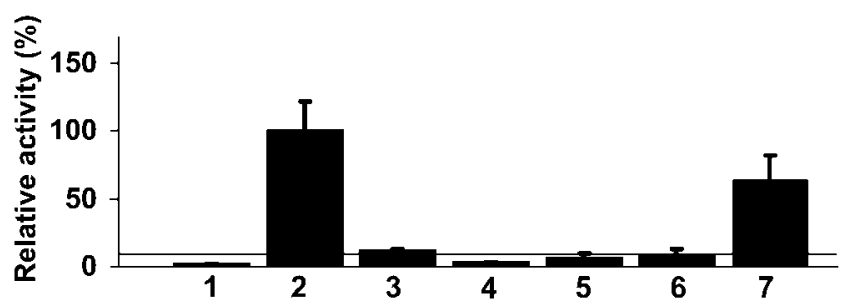

Fig. 4. Interaction between FtsW and PBP3 by the Cya bacterial two-hybrid approach, using the following: 1, E. coli BTH101 (cya) transformants producing T25 and T18 (negative control); 2, T25$\left(\mathrm{G}_{4} \mathrm{~S}\right)_{3}-\mathrm{FtsW}$ and T18- $\left(\mathrm{G}_{4} \mathrm{~S}\right)_{3}-\mathrm{PBP} 3 ; 3, \mathrm{~T} 25-\left(\mathrm{G}_{4} \mathrm{~S}\right)_{3}-\mathrm{FtsW}$ and $\mathrm{T} 18-\left(\mathrm{G}_{4} \mathrm{~S}\right)_{3}-\mathrm{PBP} 3(\mathrm{M} 1-\mathrm{V} 42) ; 4, \mathrm{~T} 25-\left(\mathrm{G}_{4} \mathrm{~S}\right)_{3}-\mathrm{FtsW}$ and T18$\left(\mathrm{G}_{4} \mathrm{~S}\right)_{3}-\mathrm{LppPBP3}$ (negative control); $5, \mathrm{~T} 25-\left(\mathrm{G}_{4} \mathrm{~S}\right)_{3}-\mathrm{FtsW}$ and $\mathrm{T} 18-\left(\mathrm{G}_{4} \mathrm{~S}\right)_{3}-\mathrm{PBP} 3(\mathrm{L39P}) ; \quad 6, \quad \mathrm{~T} 25-\left(\mathrm{G}_{4} \mathrm{~S}\right)_{3}-\mathrm{FtsW}$ and T18$\left(\mathrm{G}_{4} \mathrm{~S}\right)_{3}-\mathrm{PBP} 3(\mathrm{R} 23 \mathrm{C}) ; 7, \mathrm{~T} 25-\left(\mathrm{G}_{4} \mathrm{~S}\right)_{3}-\mathrm{FtsW}(\mathrm{P} 368 \mathrm{~A} ; \mathrm{P375A})$ and T18- $\left(\mathrm{G}_{4} \mathrm{~S}\right)_{3}-\mathrm{PBP} 3$. The $\beta$-galactosidase activity of transformants grown in LB medium in the absence of IPTG for $17 \mathrm{~h}$ at $30{ }^{\circ} \mathrm{C}$ was determined as described in Methods. Data are means \pm SD of six independent experiments. E. coli $\mathrm{BTH} 101$ transformants producing T25 with T18- $\left(\mathrm{G}_{4} \mathrm{~S}\right)_{3}-\mathrm{PBP} 3, \mathrm{~T} 18$ with $\mathrm{T} 25-\left(\mathrm{G}_{4} \mathrm{~S}\right)_{3}-\mathrm{FtsW}$ or T18 with T25 gave the same value as found for the $\beta$-galactosidase basal activity. A percentage $\beta$-galactosidase activity above the horizontal line indicates a significant interaction. 
agreement with the data obtained by immunoprecipitation (see above).

The alteration of the TMS of PBP3 strongly affects the interaction between PBP3 and FtsW (Fig. 4). The level of $\beta$ galactosidase activity of the cya-deficient E. coli BTH101 coproducing $\mathrm{T} 25-\left(\mathrm{G}_{4} \mathrm{~S}\right)_{3}-\mathrm{FtsW}$ and $\mathrm{T} 18-\left(\mathrm{G}_{4} \mathrm{~S}\right)_{3}-\mathrm{PBP} 3(\mathrm{M} 1-$ V42), T18- $\left(\mathrm{G}_{4} \mathrm{~S}\right)_{3}-\mathrm{PBP} 3(\mathrm{R} 23 \mathrm{C})$ or $\mathrm{T} 18-\left(\mathrm{G}_{4} \mathrm{~S}\right)_{3}-\mathrm{PBP} 3(\mathrm{~L} 39 \mathrm{P})$ under non-induced conditions was 12,8 and $7 \%$, respectively, of the activity of wild-type fusion proteins, whereas in the negative controls it was $2.4 \%$ of that of the wild-type. Under the conditions used, the mutant fusion proteins PBP3(R23C) and PBP3(L39P) were not immunodetected in cell extracts (data not shown). The presence of T18- $\left(\mathrm{G}_{4} \mathrm{~S}\right)_{3}-$ PBP3(M1-V42) could not be analysed (the antibodies that recognize $\mathrm{PBP} 3$ are not directed against this part of the protein). By contrast, in the presence of IPTG, T18- $\left(\mathrm{G}_{4} \mathrm{~S}\right)_{3}-$ PBP3(R23C) and T18- $\left(\mathrm{G}_{4} \mathrm{~S}\right)_{3}-\mathrm{PBP} 3(\mathrm{~L} 39 \mathrm{P})$ were immunodetected like the wild-type protein (Supplementary Fig. S1). The level of $\beta$-galactosidase activity of $E$. coli BTH101 coproducing $\mathrm{T} 25-\left(\mathrm{G}_{4} \mathrm{~S}\right)_{3}-\mathrm{FtsW}$ and $\mathrm{T} 18-\left(\mathrm{G}_{4} \mathrm{~S}\right)_{3}-\mathrm{PBP} 3(\mathrm{R} 23 \mathrm{C})$ or T18- $\left(\mathrm{G}_{4} \mathrm{~S}\right)_{3}-\mathrm{PBP} 3(\mathrm{~L} 39 \mathrm{P})$ in the presence of IPTG was 28 and $13.6 \%$, respectively, of the activity of wild-type fusion proteins, whereas in the negative controls it was $6.7 \%$ of that of the wild-type (Supplementary Fig. S2). These results indicate a very weak interaction of FtsW with the PBP3(R23C) mutant and no significant interaction with the PBP3(L39P) mutant.

To verify the interaction between the TMS of PBP3 and the FtsW protein, the interaction between a truncated PBP3 mutant expressing amino acid residues $\mathrm{K} 2$ to V42 fused to the C-terminus of $\mathrm{mKO}$ and mCherry was studied by FRET in the presence and the absence of the endogenous PBP3 protein. Strain LMC510 (Taschner et al., 1988) was transformed with $\mathrm{mKO}$ and mCherry FRET plasmids. This strain encodes a temperature-sensitive PBP3(G191D;D266N) mutant (ftsI2158) that does not localize and gives rise to a very unstable protein, undetectable by immunoblotting, at the restrictive temperature of $42{ }^{\circ} \mathrm{C}$. The wild-type mCherryPBP3 protein complemented the temperature-sensitive phenotype as expected (not shown) and interacted with FtsW at both temperatures (Fig. 5). The PBP3(K2-V42) mutant also interacted with FtsW, although not as efficiently as the intact PBP3 protein. The FRET efficiency between these proteins was slightly elevated at $42^{\circ} \mathrm{C}$ (Fig. 5), possibly

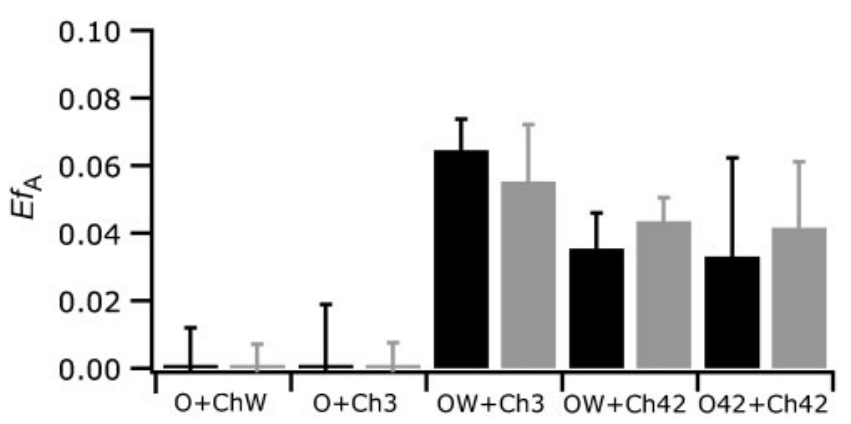

Fig. 5. Interaction between FtsW and the TMS of PBP3 confirmed by FRET. FRET efficiency $\left(E f_{A}\right)$ is shown for various combinations of $\mathrm{mKO}$ and $\mathrm{mCherry}$ fusions (for details see the legend of Fig. 2). $\mathrm{O}+\mathrm{ChW}$, expression of $\mathrm{mKO}$ and $\mathrm{mCherry-FtsW}$ (negative control); $\mathrm{O}+\mathrm{Ch} 3$, expression of $\mathrm{mKO}$ and mCherry-PBP3 (negative control); $\mathrm{OW}+\mathrm{Ch} 3$, expression of $\mathrm{mKO}-\mathrm{FtsW}$ and $\mathrm{mCh}-\mathrm{PBP} 3$; OW + Ch42, expression of $\mathrm{mKO}-\mathrm{FtsW}$ and $\mathrm{mCh}-$ PBP3(K2-V42); $\mathrm{O} 42+\mathrm{Ch} 42$, expression of mKO-PBP3(K2$\mathrm{V} 42)$ and $\mathrm{mCh}-\mathrm{PBP} 3(\mathrm{~K} 2-\mathrm{V} 42)$. The values are means $\pm \mathrm{SD}$ of three independent experiments. Black bars, $28^{\circ} \mathrm{C}$; grey bars, $42{ }^{\circ} \mathrm{C}$.

due to the absence of competing endogenous PBP3. Dimerization was found for the PBP3(K2-V42) mutants at both temperatures, which indicates that the TMS of PBP3 is sufficient for dimerization.

\section{FtsW interacts with PBP1B}

Previous investigations have shown that PBP3, PBP1B, FtsN and FtsW interact with each other in a bacterial twohybrid assay (Di Lallo et al., 2003; Karimova et al., 2005; Bertsche et al., 2006; Müller et al., 2007), but prior to this study the interaction between PBP1B and FtsW had not been investigated. We used the Cya two-hybrid system to analyse it. Table 2 shows that cells of E. coli BTH101 coexpressing T18- $\left(\mathrm{G}_{4} \mathrm{~S}\right)_{3}-\mathrm{PBP} 1 \mathrm{~B}$ (Bertsche et al., 2006) and $\mathrm{T} 25-\left(\mathrm{G}_{4} \mathrm{~S}\right)_{3}-\mathrm{FtsW}$ (Derouaux et al., 2008) produced $\beta$ galactosidase, indicating an interaction between these two proteins. To characterize the interaction, we analysed the effect of the FtsW(P368A;P375A) double mutant on the interaction with $\mathrm{PBP} 1 \mathrm{~B}$ using the two-hybrid system

Table 2. Interaction of FtsW(P368A;P375A) double mutant with PBP3, PBP1B and FtsN by the Cya two-hybrid system

The $\beta$-galactosidase activity from E. coli BTH101 (cya) transformants grown in LB medium for $17 \mathrm{~h}$ at $30{ }^{\circ} \mathrm{C}$ was determined as described in Methods. Data are means \pm SD of six independent experiments.

\begin{tabular}{|c|c|c|c|}
\hline & \multicolumn{3}{|c|}{$\beta$-Galactosidase activity (\%) } \\
\hline & $\mathrm{T} 18-\left(\mathrm{G}_{4} \mathrm{~S}\right)_{3}-\mathrm{PBP} 3$ & $\mathrm{~T} 18-\left(\mathrm{G}_{4} \mathrm{~S}\right)_{3}-\mathrm{PBP} 1 \mathrm{~B}$ & T18-FtsN \\
\hline T25- $\left(\mathrm{G}_{4} \mathrm{~S}\right)_{3}-\mathrm{FtsW}$ (wild-type) & $100 \pm 20$ & $100 \pm 36$ & $100 \pm 22$ \\
\hline T25- $\left(\mathrm{G}_{4} \mathrm{~S}\right)_{3}-\mathrm{FtsW}(\mathrm{P} 368 \mathrm{~A} ; \mathrm{P} 375 \mathrm{~A})-\mathrm{HA}$ tag & $64 \pm 18$ & $46 \pm 7$ & $118 \pm 15$ \\
\hline T25/T18 (negative control) & $2.4 \pm 0.3$ & $9 \pm 2$ & $5 \pm 1$ \\
\hline
\end{tabular}


(Table 2). The level of $\beta$-galactosidase activity due to the complementation by the Cya fusion pairs PBP1B and FtsW(P368A;P375A) was $46 \pm 7 \%$ of that of the wild-type fusion pair (Table 2). This result suggests that the $9 / 10$ loop of FtsW plays a role in the interaction with PBP1B.

Based on bacterial two-hybrid experiments, it is known that FtsW interacts with FtsN (Di Lallo et al., 2003). To determine if the effect of the P368A;P375A modification of $\mathrm{FtsW}$ is specific for the interaction with PBP1B and PBP3, we analysed the effects of the FtsW(P368A;P375A) double mutant on the interaction with FtsN. Plasmids allowing the co-production of $\mathrm{T} 25-\left(\mathrm{G}_{4} \mathrm{~S}\right)_{3}-\mathrm{FtsW}(\mathrm{P} 368 \mathrm{~A} ; \mathrm{P} 375 \mathrm{~A})$ with T18-FtsN (Müller et al., 2007) were introduced into E. coli BTH101. The FtsW(P368A;P375A) mutant appeared not to affect the interaction, since the $\beta$-galactosidase activity of the Cya fusion pair FtsW(P368A;P375A) and FtsN was $118 \% \pm 15 \%$ of that of the wild-type (Table 2 ). Thus the $9 /$ 10 loop of FtsW seems to play a role in the interactions with PBP1B and PBP3 but not in the interaction with FtsN.

\section{DISCUSSION}

\section{FtsW and PBP3 form a subcomplex}

The divisome is a dynamic hyperstructure (Norris et al., 2007). Its assembly is mediated by multiple protein interactions. Most of the protein interactions within the divisome have been detected with a two-hybrid system or by genetic methods, which cannot distinguish direct from indirect interactions. Based on these experiments, during the maturation of the divisome, the late proteins appear to be capable of associating into pre-assembled complexes FtsQ-FtsL-FtsB and FtsW-PBP3 (Goehring et al., 2006). The trimeric complex FtsQ-FtsL-FtsB has been identified by biochemical approaches in E. coli and Streptococcus pneumoniae (Buddelmeijer \& Beckwith, 2004; NoirclercSavoye et al., 2005). The results of in vivo FRET experiments presented in this work show for the first time a direct interaction between FtsW and class B PBP3 in E. coli. In addition, these proteins can be co-immunoprecipitated, demonstrating that they form a discrete complex.

The fact that the FtsW-PBP3 complex was also displayed in Mycobacterium tuberculosis indicates that this complex is a broadly conserved unit of the division machinery like the FtsQ-FtsL-FtsB complex (Goehring et al., 2006). In $M$. tuberculosis, FtsW and PBP3 formed a ternary complex with FtsZ via the FtsW C-terminal extension, which is not present in E. coli (Datta et al., 2006). In E. coli, PBP3 was shown to interact directly with ZapA, which itself binds FtsZ (Mohammadi et al., 2009; Alexeeva et al., 2010), indicating that there is also an interaction between the Zring (via ZapA) and the FtsW-PBP3 complex. During the review of this article, a direct interaction between SpoVE, a non-essential, sporulation-specific homologue of FtsW, and SpoVD, a non-essential PBP homologue to class B PBP2B of Bacillus subtilis, was also demonstrated by co-immunoprecipitations, FRET experiments and coaffinity purification in E. coli (Fay et al., 2010). All these data suggest that this interaction is conserved with SEDS/ PBP pairs (Fay et al., 2010).

\section{Interaction between FtsW and PBP3}

The interaction between FtsW and PBP3 could take place through one of the TMSs of FtsW, as the first 56 residues of PBP3 (containing the TMS) are sufficient to localize it to the division site (Piette et al., 2004). It has been shown that the peptides K2-V42 and W22-V47 of PBP3 localize, but poorly, to the division site of cells depleted of wild-type PBP3 (Piette et al., 2004; Wissel et al., 2005). Our twohybrid and FRET results show that the first 42 amino acid residues of PBP3 containing the TMS are still able to interact with FtsW, although not as efficiently as the intact $\mathrm{PBP} 3$ protein, when the proteins were overexpressed. It was observed that PBP3(R23C) and PBP3(L39P) mutants localize poorly at the division site (Wissel \& Weiss, 2004). Our results show that there is a weak or no significant interaction between FtsW and these PBP3 mutants when the proteins are overproduced and immunodetected, indicating that these residues and/or the conformation of the TMS are essential for the interaction with FtsW. Taken together, these data demonstrate that the PBP3 TMS is involved in a direct interaction with a TMS of FtsW. Therefore the first 42 amino acid residues of PBP3 appear to contain the structural determinants required for the FtsW-PBP3 interaction.

In M. tuberculosis, it was shown that the periplasmic loop 9/ 10 (residues 376-386) of FtsW (the counterpart of P368P375 of E. coli FtsW) harbours determinants crucial to the FtsW-PBP3 binding interface (Datta et al., 2006). This loop shows a strong sequence homology with that of E. coli FtsW. The E. coli FtsW(P368A;P375A) mutant, which was altered in this 9/10 loop, was co-immunoprecipitated with PBP3, although it interacts less well with PBP3. All these data suggest that the loop 9/10 of $E$. coli $\mathrm{FtsW}$ is also involved in the interaction with PBP3 in addition to a TMS.

\section{PBP3 dimers}

From our FRET experiments it can be assumed that PBP3 forms dimers in vivo and that amino acids $\mathrm{K} 2-\mathrm{V} 42$ are sufficient for dimerization, confirming the previous twohybrid results (Di Lallo et al., 2003; Karimova et al., 2005). However, on the basis of the 3D structure of the soluble form of PBP3(G57-V577), the protein appears as a monomer (E. Sauvage, personal communication). Yet the first 56 residues of $\mathrm{PBP} 3$ are targeted just like the wild-type $\mathrm{PBP} 3$ to the division site in PBP3-depleted cells (Piette et al., 2004) and are sufficient for its interaction with FtsW. In addition, it has been shown that the first 70 amino acid residues interact with FtsW as efficiently as the wild-type PBP3 (Karimova et al., 2005). All these data suggest that the region involved in the dimerization of PBP3 might consist of 
the M1-E56 peptide containing a short intracellular M1R23 peptide fused to an F24-L39 membrane anchor fused to a short periplasmic G40-E56 peptide. The dimerization region could nevertheless extend further to $\mathrm{S} 70$.

\section{Interaction between FtsW and PBP1B}

Although PBP1B interacts in vivo and in vitro with $\mathrm{PBP} 3$ and its septal localization is PBP3 dependent (Bertsche et al., 2006), the protein is not detected in the FtsW-PBP3 complex after co-immunoprecipitation. One explanation could be that the interaction between these proteins is very weak or is disrupted by the presence of detergent in the membrane extract. Indeed, the PBP1B-PBP3 complex can only be co-immunoprecipitated if $\mathrm{PBP} 1 \mathrm{~B}$ is covalently attached to PBP3 by in vivo cross-linking (Bertsche et al., 2006). It is known that PBP3, FtsN and PBP1B interact with each other and that FtsW interacts with PBP3 and FtsN. To our knowledge there is no previous report suggesting an interaction between FtsW and PBP1B. By using the Cya two-hybrid assay we have shown that FtsW interacts in vivo with the main peptidoglycan synthase PBP1B. This interaction might be indirect. Alteration of the P368-P375 periplasmic loop 9/10 of FtsW which is involved in the recruitment of $\mathrm{PBP} 3$ at the division site (Pastoret et al., 2004) reduces the interaction with PBP1B 2 -fold, and the interaction with PBP3 1.5-fold, but has no effect on the interaction with FtsN. This loop thus appears to play a role in the interaction with both PBP1B and PBP3 and might be involved in the correct positioning of the proteins in the divisome.

Our results demonstrate that FtsW and PBP3 form a conserved subcomplex within the divisome. Although FtsW interacts with $\mathrm{PBP} 1 \mathrm{~B}$, an FtsW-PBP3-PBP1B trimeric complex could not be detected, probably because the interactions are not strong enough or are transient.

\section{ACKNOWLEDGEMENTS}

We thank David Weiss, University of Iowa, USA, for plasmids allowing production of R23C and L39P PBP3 mutants, Daniel Ladant for providing the cya E. coli strain and Roger Y. Tsien for providing the pRSETBmCherry plasmid. This project was supported by the Belgian Programme on Interuniversity Poles of Attraction initiated by the Belgian State, Prime Minister's Office, Science Policy Programming (IAP 6/19), by the Fonds de la Recherche Fondamentale Collective (Contract 2.4543.05), by a Dutch NWO 'Van Molecuul tot Cel' programme grant ALW 805.47.200 (S. A. and T. d. B.) by a Vernieuwingsimpuls grant 016.001-024 (T. d. B.) and by the European Commission within the EUR-INTAFAR network (SHM-CT-2004-512138). This work was funded in part by European Framework Programs DIVINOCELL HEALTH F3-2009223431 (T.d.B. and R.v.P).

\section{REFERENCES}

Aarsman, M. E., Piette, A., Fraipont, C., Vinkenvleugel, T. M., Nguyen-Distèche, M. \& den Blaauwen, T. (2005). Maturation of the Escherichia coli divisome occurs in two steps. Mol Microbiol 55, 1631-1645.

Addinall, S. G. \& Lutkenhaus, J. (1996). FtsA is localized to the septum in an FtsZ-dependent manner. J Bacteriol 178, 7167-7172.

Alexeeva, S., Gadella, T. W. J., Verheul, J., Verhoeven, G. S. \& den Blaauwen, T. (2010). Direct interactions of early and late assembling division proteins in Escherichia coli cells resolved by FRET. Mol Microbiol 77, 384-398.

Begg, K. J., Takasuga, A., Edwards, D. H., Dewar, S. J., Spratt, B. G., Adachi, H., Ohta, T., Matsuzawa, H. \& Donachie, W. D. (1990). The balance between different peptidoglycan precursors determines whether Escherichia coli cells will elongate or divide. J Bacteriol 172, 6697-6703.

Bertsche, U., Kast, T., Wolf, B., Fraipont, C., Aarsman, M. E., Kannenberg, K., von Rechenberg, M., Nguyen-Distèche, M., den Blaauwen, T. \& other authors (2006). Interaction between two murein (peptidoglycan) synthases, PBP3 and PBP1B, in Escherichia coli. Mol Microbiol 61, 675-690.

Buddelmeijer, N. \& Beckwith, J. (2004). A complex of the Escherichia coli cell division proteins FtsL, FtsB and FtsQ forms independently of its localization to the septal region. Mol Microbiol 52, 1315-1327.

Clegg, R. M. (1992). Fluorescence resonance energy transfer and nucleic acids. Methods Enzymol 211, 353-388.

Clegg, R. M., Murchie, A. I., Zechel, A., Carlberg, C., Diekmann, S. \& Lilley, D. M. (1992). Fluorescence resonance energy transfer analysis of the structure of the four-way DNA junction. Biochemistry 31, 48464856.

Datta, P., Dasgupta, A., Singh, A. K., Mukherjee, P., Kundu, M. \& Basu, J. (2006). Interaction between FtsW and penicillin-binding protein 3 (PBP3) directs PBP3 to mid-cell, controls cell septation and mediates the formation of a trimeric complex involving FtsZ, FtsW and PBP3 in mycobacteria. Mol Microbiol 62, 1655-1673.

den Blaauwen, T., de Pedro, M. A., Nguyen-Distèche, M. \& Ayala, J. A. (2008). Morphogenesis of rod-shaped sacculi. FEMS Microbiol Rev 32, 321-344.

Derouaux, A., Wolf, B., Fraipont, C., Breukink, E., Nguyen-Distèche, M. \& Terrak, M. (2008). The monofunctional glycosyltransferase of Escherichia coli localizes to the cell division site and interacts with penicillin-binding protein 3, FtsW, and FtsN. J Bacteriol 190, 1831-1834.

Di Lallo, G., Fagioli, M., Barionovi, D., Ghelardini, P. \& Paolozzi, L. (2003). Use of a two-hybrid assay to study the assembly of a complex multicomponent protein machinery: bacterial septosome differentiation. Microbiology 149, 3353-3359.

Errington, J. (2003). Dynamic proteins and a cytoskeleton in bacteria. Nat Cell Biol 5, 175-178.

Fay, A., Meyer, P. \& Dworkin, J. (2010). Interactions between late acting proteins required for peptidoglycan synthesis during sporulation. J Mol Biol 399, 547-561.

Förster, T. (1948). Zwischenmolekulare Energiewanderung und Fluoreszenz [Intermolecular energy migration and fluorescence]. Annalen der Physik 2, 55-75.

Gadella, T. W. J. (2009). FRET and FLIM imaging techniques. In Laboratory Techniques in Biochemistry and Molecular Biology, pp. 148. Edited by P. C. Van der Vliet. Burlington: Academic Press.

Goehring, N. W., Gonzalez, M. D. \& Beckwith, J. (2006). Premature targeting of cell division proteins to midcell reveals hierarchies of protein interactions involved in divisome assembly. Mol Microbiol 61, 33-45.

Goffin, C. \& Ghuysen, J. M. (1998). Multimodular penicillin-binding proteins: an enigmatic family of orthologs and paralogs. Microbiol Mol Biol Rev 62, 1079-1093. 
Henriques, A. O., Glaser, P., Piggot, P. J. \& Moran, C. P. (1998). Control of cell shape and elongation by the $\operatorname{rodA}$ gene in Bacillus subtilis. Mol Microbiol 28, 235-247.

Höltje, J. V. (1998). Growth of the stress-bearing and shapemaintaining murein sacculus of Escherichia coli. Microbiol Mol Biol Rev 62, 181-203.

Karasawa, S., Araki, T., Nagai, T., Mizuno, H. \& Miyawaki, A. (2004). Cyan-emitting and orange-emitting fluorescent proteins as a donor/ acceptor pair for fluorescence resonance energy transfer. Biochem J 381, 307-312.

Karimova, G., Dautin, N. \& Ladant, D. (2005). Interaction network among Escherichia coli membrane proteins involved in cell division as revealed by bacterial two-hybrid analysis. J Bacteriol 187, 22332243.

Lara, B. \& Ayala, J. A. (2002). Topological characterization of the essential Escherichia coli cell division protein FtsW. FEMS Microbiol Lett 216, 23-32.

Löwe, J. \& Amos, L. A. (1998). Crystal structure of the bacterial celldivision protein FtsZ. Nature 391, 203-206.

Margolin, W. (2000). Themes and variations in prokaryotic cell division. FEMS Microbiol Rev 24, 531-548.

Matsuhashi, M. (1994). Utilization of lipid-linked precursors and the formation of peptidoglycan in the process of cell growth and division: membrane enzymes involved in the final steps of peptidoglycan synthesis and the mechanism of their regulation. In Bacterial Cell Wall (New Comprehensive Biochemistry, vol. 27), pp. 55-71. Edited by J. M. Ghuysen \& R. Hakenbeck. Amsterdam: Elsevier.

Mercer, K. L. \& Weiss, D. S. (2002). The Escherichia coli cell division protein $\mathrm{FtsW}$ is required to recruit its cognate transpeptidase, FtsI (PBP3), to the division site. J Bacteriol 184, 904-912.

Mohammadi, T., Ploeger, G. E., Verheul, J., Comvalius, A. D., Martos, A., Alfonso, C., van Marle, J., Rivas, G. \& den Blaauwen, T. (2009). The GTPase activity of Escherichia coli FtsZ determines the magnitude of the FtsZ polymer bundling by ZapA in vitro. Biochemistry 48, 11056-11066.

Müller, P., Ewers, C., Bertsche, U., Anstett, M., Kallis, T., Breukink, E., Fraipont, C., Terrak, M., Nguyen-Distèche, M. \& Vollmer, W. (2007). The essential cell division protein FtsN interacts with the murein (peptidoglycan) synthase PBP1B in Escherichia coli. J Biol Chem 282, 36394-36402.

Nanninga, N. (1998). Morphogenesis of Escherichia coli. Microbiol Mol Biol Rev 62, 110-129.
Noirclerc-Savoye, M., Le Gouëllec, A., Morlot, C., Dideberg, O., Vernet, T. \& Zapun, A. (2005). In vitro reconstitution of a trimeric complex of DivIB, DivIC and FtsL, and their transient co-localization at the division site in Streptococcus pneumoniae. Mol Microbiol 55, 413-424.

Norris, V., den Blaauwen, T., Cabin-Flaman, A., Doi, R. H., Harshey, R., Janniere, L., Jimenez-Sanchez, A., Jin, D. J., Levin, P. A. \& other authors (2007). Functional taxonomy of bacterial hyperstructures. Microbiol Mol Biol Rev 71, 230-253.

Pastoret, S., Fraipont, C., den Blaauwen, T., Wolf, B., Aarsman, M. E., Piette, A., Thomas, A., Brasseur, R. \& Nguyen-Distèche, M. (2004). Functional analysis of the cell division protein FtsW of Escherichia coli. J Bacteriol 186, 8370-8379.

Piette, A., Fraipont, C., Den Blaauwen, T., Aarsman, M. E., Pastoret, S. \& Nguyen-Distèche, M. (2004). Structural determinants required to target penicillin-binding protein 3 to the septum of Escherichia coli. J Bacteriol 186, 6110-6117.

Sauvage, E., Kerff, F., Terrak, M., Ayala, J. A. \& Charlier, P. (2008). The penicillin-binding proteins: structure and role in peptidoglycan biosynthesis. FEMS Microbiol Rev 32, 234-258.

Shaner, N. C., Campbell, R. E., Steinbach, P. A., Giepmans, B. N., Palmer, A. E. \& Tsien, R. Y. (2004). Improved monomeric red, orange and yellow fluorescent proteins derived from Discosoma sp. red fluorescent protein. Nat Biotechnol 22, 1567-1572.

Suzuki, H., Nishimura, Y. \& Hirota, Y. (1978). On the process of cellular division in Escherichia coli: a series of mutants of E. coli altered in the penicillin-binding proteins. Proc Natl Acad Sci U S A 75, 664-668.

Taschner, P. E., Huls, P. G., Pas, E. \& Woldringh, C. L. (1988). Division behavior and shape changes in isogenic fts $Z$, fts $Q, f t s A, p b p B$, and ftsE cell division mutants of Escherichia coli during temperature shift experiments. J Bacteriol 170, 1533-1540.

Weiss, D. S., Chen, J. C., Ghigo, J. M., Boyd, D. \& Beckwith, J. (1999). Localization of FtsI (PBP3) to the septal ring requires its membrane anchor, the $\mathrm{Z}$ ring, FtsA, FtsQ, and FtsL. J Bacteriol 181, 508-520.

Wissel, M. C. \& Weiss, D. S. (2004). Genetic analysis of the cell division protein FtsI (PBP3): amino acid substitutions that impair septal localization of FtsI and recruitment of FtsN. J Bacteriol 186, 490-502.

Wissel, M. C., Wendt, J. L., Mitchell, C. J. \& Weiss, D. S. (2005). The transmembrane helix of the Escherichia coli division protein FtsI localizes to the septal ring. J Bacteriol 187, 320-328.

Edited by: J. M. van Dijl 